\title{
Optimising Wellbeing in Patients with Diabetic Foot Ulcers
}

\section{Living with diabetic foot ulceration can have a significant impact on} a person's physical and psychological health. All members of the multidisciplinary team have a responsibility to consider the importance of wellbeing assessment and to be mindful of a number of suggested approaches.

\section{ABSTRACT \\ Background}

Living with diabetic foot ulceration (DFU) can have a significant impact on a person's physical and psychological health. Clinicians involved in the treatment of DFU patients should possess sufficient knowledge and understanding of the total impact of living with a DFU, including an awareness of an individual's wellbeing.

\section{Aim}

To provide an overview of the current literature with regard to wellbeing in patients affected by DFU by considering current outcome measures used to assess domains of wellbeing in this population.

\section{Findings}

The psychological, physical, spiritual, and cultural domains of wellbeing all impact an individual's overall wellbeing. There is no one standardised tool available that assesses all four domains of wellbeing specific to those with DFU. It is important for clinicians to be aware that all members of the multidisciplinary team have a responsibility to consider the importance of wellbeing assessment and to be mindful of suggested approaches.

\section{Conclusions}

There is a need for a reliable and valid measurement tool to assess overall wellbeing in people living with DFU.

\section{Implications for clinical practice}

This review highlights the importance of the inclusion of wellbeing assessment in optimising wound care for individuals with DFU.

\section{INTRODUCTION}

In recent decades, the prevalence of diabetes has increased in virtually all regions across the globe. ${ }^{1}$ The increased prevalence of diabetes and the fact that diabetic patients are living longer with the disease will undoubtedly give rise to a higher incidence of diabetes-specific complications, including cardiovascular disease, renal failure, and diabetic foot disease. ${ }^{1}$

The impact of living with diabetes and diabetic foot disease is complex and multifactorial. Diabetic foot disease can be defined as the presence of several characteristic diabetic foot complications that may be comprised of neuropathies, ischaemia, infection, and Charcot's neuroarthropathy. ${ }^{2}$ Diabetic foot disease is associated with devastating outcomes such as diabetic foot ulceration (DFU), amputation, and premature death. A DFU is a pivotal event in the life of a person with diabetes and is a marker of serious disease. ${ }^{3}$ Patients with DFU are likely to have a reduced health-related quality of life (HRQoL) and are likely to experience symptoms of neuropathic pain, reduced mobility, sleep disturbances, leakage, and malodour from the wound. ${ }^{4}$

The psychological impact of living with DFU must be addressed within patient-centred management plans. Patients living with DFU are at greater risk of depression, anxiety, mood disorders, embarrassment, stigma, and issues associated with low self-esteem. ${ }^{4}$ Psychosocial factors, such as anxiety and depression, are associated with de-

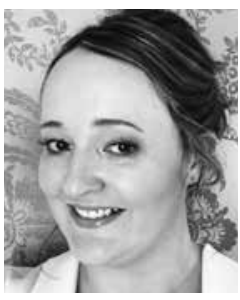

Caroline Mclntosh, $\mathrm{PhD}^{1}$

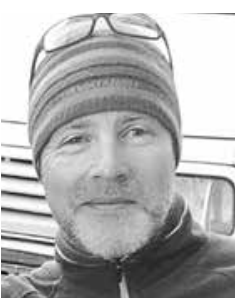

John D. Ivory, MSc ${ }^{2}$

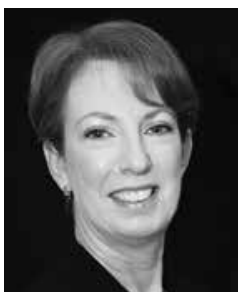

Georgina Gethin, $\mathrm{PhD}, \mathrm{RGN}^{3}$

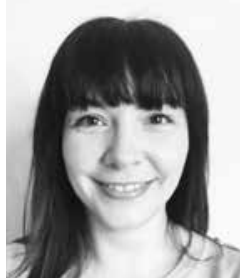

Claire MacGilchrist, $\mathrm{PhD}^{4}$

1. Professor of Podiatric Medicine, Discipline of Podiatric Medicine and the Alliance for Research and Innovation in

Wounds, National University of Ireland Galway, Galway, Ireland.

2. Research Assistant (Wound Care), School of Nursing and Midwifery and the Alliance for Research and Innovation in Wounds, National University of Ireland Galway, Galway, Ireland.

3. Head of the School of Nursing and Midwifery and the Alliance for Research and Innovation in Wounds, National University of Ireland, Galway, Ireland.

4. Lecturer in Podiatric Medicine, Discipline of Podiatric Medicine and the Alliance for Research and Innovation in Wounds, $\mathrm{Na}$ tional University of Ireland Galway, Galway, Ireland

Correspondence: caroline.mcintosh@ nuigalway.ie

Conflicts of interest: None 
layed healing, while poor symptom management can cause patients to become non-concordant. ${ }^{5}$

Evidence shows that when individual patients are actively involved in their care, outcomes improve. ${ }^{5}$ Treatment goals should, therefore, aim to optimise wellbeing and fully engage patients in their treatment. However, while the physical aspects of diabetes and DFU can be easily measured, the concept of 'wellbeing' for those living with DFU is more difficult to capture. ${ }^{5}$ For example, in those with DFU, wellbeing may be adversely affected by nonhealing wounds, while patients with healed ulcers may have a poorer HRQoL due to fear of recurrence, amputation, and/or the need for lifelong treatment. ${ }^{5,6}$

\section{HRQOL AND WELLBEING}

HRQoL is a health concept that represents the ultimate goal of health promotion interventions. ${ }^{7}$ The Center for Disease Control and Prevention (2011) defines HRQoL as an "individual's cognitive appraisal of their standard of living in relation to their health", and wellbeing specifically relates to "the existence of positive emotions and contentment, alongside the absence of persistent negative emo-

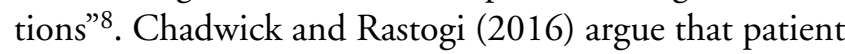
wellbeing should be considered as a separate, but linked, concept to HRQoL. ${ }^{4}$

DFU management should aim to achieve rapid wound closure and minimise complications and adverse outcomes, while restoring a patient's HRQoL to "pre-ulcer" status. 9 However, a dearth of literature exists with regard to DFU and wellbeing and there is a distinct lack of tools to measure wellbeing in this population. Yet, failure to address patient wellbeing can adversely affect clinical and patient outcomes and have negative impacts on health behaviours.

\section{DEFINING WELLBEING}

Wellbeing has been defined as: "a dynamic matrix of factors, including physical, social, psychological and spiritual. The concept of wellbeing is inherently individual, will vary over time, is influenced by culture and context, and is independent of wound type, duration or care setting". 5

\section{DOMAINS OF WELLBEING}

An individual's wellbeing encompasses physical, social, psychological, and spiritual domains that can all vary over time. ${ }^{5}$ The physical, social, and psychological factors associated with wellbeing are considered interrelated.

\section{Physical Wellbeing}

Physical wellbeing relates to an individual's ability to partake in normal activities of daily living, such as self-hygiene and dressing and feeding oneself. Specific physical parameters of a wound that impact wellbeing can include size, location, depth, and duration of the wound. ${ }^{10}$ Pain is considered one of the most distressing symptoms associated with living with a wound. ${ }^{11}$ Other commonly reported physical symptoms include wound exudate, malodour, and reduced mobility that, in isolation or collectively, may result in reduced social contact and sleep disturbances. ${ }^{12}$

\section{Psychological Wellbeing}

The psychological impact of living with a chronic wound can be difficult to measure and less tangible than the physical challenges that are associated with the wound. Despite this, the psychological impact of living with a chronic wound is suggested to be of equal importance to and interrelated with the physical symptoms. ${ }^{13}$ The aforementioned physical parameters can result in negative emotional states, such as anxiety and depression, impacting an individual's body image and self-esteem, ultimately affecting their overall psychological wellbeing. ${ }^{14}$ This negative emotional state may perpetuate further negative health behaviours such as poor nutritional choices, excessive alcohol consumption, and cigarette smoking. ${ }^{15}$ There is also evidence to suggest that in turn, this psychological stress can impair wound healing and, although further research is warranted, current evidence suggests that psychological interventions may play a role in the wound healing arena. ${ }^{16}$

\section{Social Wellbeing}

Living with a chronic wound can significantly affect social wellbeing. Limited mobility associated with a wound may prevent social interactions with some individuals rendered bed/house bound. Physical and psychological parameters can impact social interactions. For example, pain, malodour, excess exudate production, anxiety, and depression can all impact social wellbeing. ${ }^{13}$ Remaining in the work force may also be a significant challenge for individuals due to altered mobility and frequent hospital/clinical appointments associated with a wound management regime. This can result in a loss of independence and reduced quality of life. ${ }^{17}$

\section{Spiritual/Cultural Wellbeing}

An individual's perception of their wound and their expectations for healing can be largely impacted by their spiritual and cultural influences. ${ }^{5}$ Clinicians should be mindful of religious/cultural implications and involve the patient in the management plan to ensure a holistic approach. An individual's cultural and spiritual beliefs can have a powerful influence on a patient's involvement and their interaction with the care provider. ${ }^{5}$ It is important that the clinician recognises this and works with the patient accordingly.

To achieve optimal patient care, the clinician must be aware of the complex interactions between the physical, 
psychological, social, and spiritual/cultural domains of wellbeing.

\section{BARRIERS TO ASSESSING PATIENT WELLBEING}

Improving health and wellbeing is associated with economic and social benefits. ${ }^{5}$ Yet there is a lack of research that specifically focuses on the assessment of wellbeing for patients living with DFU. Therefore, assessment of patient wellbeing in this population is frequently overlooked in clinical practice. Indeed, there may be many barriers that prevent clinicians from assessing wellbeing in this cohort that may include: a lack of time in busy clinical services, lack of privacy, lack of standardised documentation, no standardised tool to capture or measure wellbeing, different professionals involved in the care of the DFU patient,

Table 1.

Summary of outcome measures associated with aspects of wellbeing in diabetic foot ulceration (DFU) patients.

\begin{tabular}{|c|c|c|c|}
\hline OUTCOME MEASURE & PUBLICATION & DOMAIN OF WELLBEING & KEY FINDINGS \\
\hline Herth Hope Index (HHI) & $\begin{array}{l}\text { Salomé et al } 2017^{19} \\
\text { Salomé et al } 2013^{20}\end{array}$ & Spiritual & $\begin{array}{l}\text { DFU patients presented } \\
\text { low senses of hope and } \\
\text { spirituality. } \\
\text { DFU patients presented } \\
\text { less hope of recovery than } \\
\text { those with VLUs. }\end{array}$ \\
\hline $\begin{array}{l}\text { Spirituality Self-rating } \\
\text { Scale (SSRS), }\end{array}$ & $\begin{array}{l}\text { Salomé et al } 2017^{19} \\
\text { Salomé et al } 2013^{21}\end{array}$ & Spiritual & $\begin{array}{l}\text { DFU patients presented } \\
\text { low senses of hope and } \\
\text { spirituality. } \\
\text { DFU patients presented } \\
\text { poorer spirituality. }\end{array}$ \\
\hline $\begin{array}{l}\text { Beck Depression } \\
\text { Inventory (BDI) }\end{array}$ & Salomé et al 201122 & Psychological (Depression) & $\begin{array}{l}\text { DFU patients presented } \\
\text { varying degrees of } \\
\text { depressive symptoms. }\end{array}$ \\
\hline $\begin{array}{l}\text { Powerlessness Assessment } \\
\text { Tool (PAT) }\end{array}$ & $\begin{array}{l}\text { De Almeida et al } 2014^{24} \\
\text { Salomé et al } 2013^{20}\end{array}$ & $\begin{array}{l}\text { Psychological } \\
\text { (Powerlessness) }\end{array}$ & $\begin{array}{l}\text { Stronger feelings of } \\
\text { powerlessness in patients } \\
\text { with DFUs than with VLUs. } \\
\text { DFU patients presented } \\
\text { stronger feelings of } \\
\text { powerlessness and less } \\
\text { hope of recovery than } \\
\text { those with VLUs. }\end{array}$ \\
\hline $\begin{array}{l}\text { The Pittsburgh Sleep } \\
\text { Quality Index (PSQI) }\end{array}$ & Salomé et al $2013^{25}$ & Physical (Sleep) & $\begin{array}{l}\text { DFU patients have } \\
\text { poor sleep quality. }\end{array}$ \\
\hline $\begin{array}{l}\text { Rosenberg Self- } \\
\text { Esteem Scale }\end{array}$ & Salomé et al $2011^{23}$ & Psychological (Self-Esteem) & $\begin{array}{l}\text { Foot ulcers have a } \\
\text { negative impact on the } \\
\text { self-esteem of patients } \\
\text { with diabetes. }\end{array}$ \\
\hline $\begin{array}{l}\text { Cardiff Wound } \\
\text { Impact Schedule (CWIS) }\end{array}$ & Ogrin et al $2015^{27}$ & Overall wellbeing & $\begin{array}{l}\text { A statistically significant } \\
\text { improvement in well- } \\
\text { being followed closure of } \\
\text { DFUs compared to base- } \\
\text { line. }\end{array}$ \\
\hline
\end{tabular}


or individuals may not want to discuss such issues for fear of "bothering" the clinician or worrying that the clinician may judge them. ${ }^{5}$

\section{OUTCOME MEASURES}

Published research in this area, specifically with regard to DFU, has primarily focused on HRQoL rather than on the specific domains of wellbeing. A recent position paper highlighted the importance of and the need for wellbeing to be included in future wound care research. ${ }^{18} \mathrm{HRQoL}$ tools typically focus on limitations caused by physical functioning, rather than assessing positive emotions associated with wellbeing, such as optimism, life satisfaction, possession of coping skills, and hope for the future. ${ }^{18}$

Several studies have investigated individual aspects of wellbeing in patients with DFUs (Table 1). The spiritual domain can be measured by considering an individual's sense of hope. ${ }^{19,20}$ Often the idea of 'loss of independence' emerges during the assessment of this domain. ${ }^{21}$

The psychological domain is associated with symptoms such as anxiety, depression ${ }^{22}$, grief, body image distortion, and self-esteem issues ${ }^{23}$ that can all contribute to an overall feeling of 'powerlessness'. ${ }^{24}$ Most frequently reported in the literature are elements of the physical domain as various outcome measures can be used to report physical symptoms such as lack of sleep ${ }^{25}$, pain, exudate, and mobility issues. The aforementioned domains can influence the social domain, where individuals may be less likely to integrate into society due to the implication of living with a wound.

Several domains of wellbeing have been previously assessed with regard to DFU (Table 1). However, there is no one standardised tool that takes a holistic approach to assess the overall wellbeing of patients with DFUs. The Wellbeing in Wounds Inventory is considered among the first to holistically assess wellbeing and has been demonstrated to be a valid and reliable measure of wellbeing for patients living with chronic wounds. ${ }^{26,27}$ However, this is a generic outcome measure for use in patients with chronic wounds. The lack of a diabetes-specific wellbeing assessment tool should be an area for further research.

\section{CURRENT STRATEGIES TO OPTIMISE PATIENT WELLBEING}

Involving patients in their own care is an increasingly recognised concept. Patient involvement can be defined as follows:

For patients: "Being active in the management of their own health and health care, and in any decisions made about available treatment options". ${ }^{28}$
For clinicians: "Knowing who their patients are and developing a partnership that facilitates a transparency of information for both parties". ${ }^{28}$

\section{NOVEL STRATEGIES TO ADDRESS DFU PATIENT WELLBEING}

\section{Build a Therapeutic Relationship}

Effective communication is central to optimum patientcentred care. Developing an environment that is caring, competent, and compassionate is paramount to establishing an equitable relationship between patient and clinician. Clinicians can begin to establish effective therapeutic relationships by establishing their patients' trust, recognising the patient 'as a person,' and being a true advocate for optimum patient-centred care. ${ }^{5}$

\section{Ask Trigger Questions}

The following trigger questions have been suggested to assess wellbeing in those living with chronic wounds: ${ }^{5}$

1. Has your wound improved or worsened? Please describe. If new, how did it happen?

2. Has your wound stopped you from doing things in the last week? If so, what?

3. What causes you the most disturbance/distress and when does this occur?

4. Do you have anyone to help you cope with your wound?

5. What would help to ease/improve your daily experience of living with a wound?

\section{Patient Empowerment and Choice}

There is evidence to suggest that the more control one has over a situation the less likely one is to suffer from stress and pain. Thus, if patients have control of or influence over their condition, they will more likely engage in self-care of their DFU. ${ }^{29}$ Thus, healthcare practitioners must empower patients to take control of their condition, wounds, and treatment. ${ }^{30}$ Patients should be encouraged to openly discuss treatment options or concerns as this can improve self-management strategies and increase concordance with treatment regimes.

It is important to consider that the effect of an individuals' wound on wellbeing can be time dependant; thus, on-going, frequent assessment is key to accurately capture the domains of wellbeing. The clinician should ensure that when asking questions, the questions are individualised with a specific focus on the patients' specific concerns in relation to the impact of living with their wound. ${ }^{5}$ It may 
be that generic approaches used to capture wellbeing are appropriate for other types of chronic wounds, but do not sufficiently address the diabetes-specific challenges faced by those living with DFU.

\section{Team Approach}

All members of the multi-disciplinary team should actively be involved in assessing patient wellbeing. There is a need for a standardised approach to allow for an effective evaluation of patient wellbeing, while ensuring that the clinician creates an appropriate environment to encourage this dialogue. Suitable occasions for this may be during home visits or routine clinical appointments to provide an opportunity for these more relaxed, informal conversations. ${ }^{5}$

\section{IMPLICATIONS FOR CLINICAL PRACTICE}

- DFUs can impact all domains of patient wellbeing (physical, psychological, social, and spiritual/cultural).

- People living with DFUs are at greater risk of depression, anxiety, mood disorders, embarrassment, stigma, and low self-esteem.

- Negative emotional states may perpetuate negative health behaviours in this population, resulting in poor clinical and patient outcomes.

- Patient wellbeing should be assessed and measured as part of a patient-centred, holistic, wound management plan.

- Current assessment tools are mainly generic for chronic wounds and only address certain parameters of wellbeing. There are currently no assessment tools specific for measuring wellbeing in DFU patients.

\section{FUTURE RESEARCH}

- There is a need to develop a valid and reliable assessment tool to measure the various domains of wellbeing in patients with DFU.

- Public and patient involvement in research would be an ideal methodological approach to explore wellbeing in patients with DFU.

- A valid and reliable measure of wellbeing in patients with DFU would aid clinicians in optimising health care and improving patient outcomes in those affected with DFU.

\section{CONCLUSIONS}

A dearth of literature exists with regard to wellbeing in patients with DFU, and there is a distinct lack of tools to measure overall wellbeing in this population. Failure to address patient wellbeing adversely affects clinical and patient outcomes and has the potential to negatively impact health behaviours. Future research should further explore the concept of wellbeing in patients living with DFUs. There is a need through novel methodological approaches, including patient and public involvement in research, to develop a meaningful, specific, patient-centred wellbeing assessment tool to effectively measure wellbeing in those living with DFU. 


\section{REFERENCES}

1. Harding, JL. Pavkov, ME. Magliano, DJ. Shaw, JE. Gregg, EW. Global trends in diabetes complications: a review of current evidence, Diabetologia, 2019, 62: 3-16.

2. McIntosh, C. Impaired Wound Healing in the Diabetic Foot Wound Essentials, 2017, 12 (1); 52-56.

3. International Best Practice Guidelines: Wound Management in Diabetic Foot Ulcers, Wounds International, 2013.

4. World Union of Wound Healing Societies (WUWHS) Florence Congress, Position Document, Local management of diabetic foot ulcers, Wounds International, 2016.

5. International Consensus, Optimising wellbeing in people living with a wound. An expert working group review. London. Wounds International. 2012. Available from: http://www.woundsinternational.com

6. Jeffcoate, WJ Vileikyte, L. Boyko, EJ Armstrong, DG Boulton, AJM. Current Challenges in the Prevention and Management of Diabetic Foot Ulcers, Diabetes Care, 2018: 41: 645-652.

7. World Health Organisation (1997) WHOQOL Measuring Quality of Life. Available at: https://www. whoint/healthinfo/survey/whoqol-qualityoflife/en (Accessed January 2019).

8. Centre for Disease Control and Prevention: Well-being Concepts (2011). Available at: https://www.cdc.gov/ $\mathrm{hrqol} /$ wellbeing.htm (Accessed January 2019).

9. Guest, JF. Fuller, GW. Vowden, P. Diabetic foot ulcer management in clinical practice in the UK: costs and outcomes, International Wound Journal, 2017.

10. European Wound Management Association. Position Document. Hard to heal wounds: a holistic approach MEP Ltd, London 2008

11. Mudge E, Spanou C, Price P. A focus group study into patients' perceptions of chronic wound pain. Wounds UK 2008; 4 (2): 21-28.
12. Cole-King A, Harding KG. Psychological factors and delayed healing in chronic wounds. Psychosom Med 2001; 63 (2): 216-20

13. Upton $D$, South $F$. The psychological consequences of wounds - a vicious circle that should not be overlooked. Wounds UK 2011; 7 (4): 136-138.

14. Guo S, DiPietro LA. Factors affecting wound healing. J Dent Res 2010; 89(3): 219-29.

15. Gouin JP, Kiecolt-Glaser JK. The impact of psychological stress on wound healing: methods and mechanisms. Immunol Allergy Clin North Am 2011; 31 (1): 81-93

16. Robinson $H$, Norton $S$, Jarret $P$, Broadbent $E$. The effects of psychological interventions on wound healing: A systematic review of randomized trials. $\mathrm{Br}$ healing: A systematic review of randomized
of Health Psychology 2017; 22: 805-835.

17. Goreki C, Brown J, Nelson EA et al. Impact of pressure ulcers on quality of life in older patients. J AM Geriatr Soc 2009; 57 (7): 1175-83

18. Upton D, Andrews A, Upton P. Venous leg ulcers: What about well-being? J Wound Care 2014; 23 (1): 14-17.

19. Salomé GM, de Almeida SA, Mendes B, de Carvalho MR, Bueno JC, Massahud MR Jr, Ferreira LM. Association of Sociodemographic Factors with Spirituality and Hope in Patients with Diabetic Foot Ulcers. Adv Skin Wound Care 2017; 30(1): 34-39.

20. Salomé GM, Alves SG, Costa VF, Pereira VR, Ferreira LM. Feelings of powerlessness and hope for cure in patients with chronic lower-limb ulcers. J Wound Care 2013; 22(6): $300-04$.

21. Salomé GM, Pereira VR, Ferreira LM. Spirituality and subjective wellbeing in patients with lower-limb ulceration. J Wound Care 2013 May; 22(5): 230-36.

22. Salomé GM, Blanes L, Ferreira LM. Assessment of depressive symptoms in people with diabetes mellitus and foot ulcers. Rev Col Bras Cir 2011; 38(5):327-33.
23. Salomé GM, Maria de Souza Pellegrino D, Blanes $L$, Ferreira LM. Self-esteem in patients with diabetes mellitus and foot ulcers. J Tissue Viability 2011 20(3): 100-6.

24. De Almeida SA, Salomé GM, Dutra RA, Ferreira LM Feelings of powerlessness in individuals with either venous or diabetic foot ulcers. J Tissue Viability 2014; 23(3): 109-14.

25. Salomé GM, de Souza Pellegrino DM, Blanes $L$, Ferreira LM. Sleep Quality in Patients with Diabetic Foot Ulcers. Wounds. 2013;25(1): 20-7.

26. Upton D, Upton $P$, Alexander R. Well-being in wounds inventory (WOWI): development of a valid and reliable measure of well-being in patients with wounds. J Wound Care 2016; 25(3): 1-6.

27. Orgin R, Houghton PE, Thompson GW. Effective management of patients with diabetes foot ulcers: outcomes of an Interprofessional Diabetes Foot Ulcer Team. Int Wound J 2015; 12: 377-86.

28. International Best Practice Statement: Optimising patient involvement in wound management. Wounds International, 2016: 1-19.

29. Vedhara K, Dawe K, Wetherell MA, Miles JN, Cullum N, Dayan C, Drake N, Price P, Tarlton J, Weinman J, Day A, Campbell R. Illness beliefs predict self-care behaviours in patients with diabetic foot ulcers: a prospective study. Diabetes Res Clin Pract. 2014 Oct; 106(1):67-72.

30. Upton, D. Pain, wound Care and psychology: the missing link? Wounds UK, 2011, (7) 2: 119-122. 